\title{
9. Homicide of Children
}

\author{
Theresia Höynck, Ulrike Zähringer
}

\subsection{State of knowledge}

The only official sources on the extent of homicidal crime in Germany are the Police Crime Statistics and cause of death statistics. Both have severe limitations with regard to information value and therefore do not lend themselves to systematic analysis even in respect of reported crime. Cause of death statistics are based on death certificates issued by doctors ${ }^{1}$ stating diseases leading to death and any other causes of death. The age groups used for children are $<1,1$ to $<5,5$ to $<10$ and 10 to $<15$. Injury by another person with intent to harm or kill is given as 'assault'2 regardless of how the injury is inflicted.

The Police Crime Statistics classify child and adolescent victims in even broader age groups: 0 to $<6,6$ to $<14$ and 14 to $<18$. It is also impossible to connect different characteristics beyond the small amount of detail provided in the Police Crime Statistics, since they don't offer individual case information. For example, it is not possible to tell from the Police Crime Statistics if offender-victim relationships differ between age groups. Being compiled of a specific reporting date, the Police Crime Statistics also have the problem that they only include what the police stated at the end of their investigations and do not reflect whether a case is later dropped by the prosecution service or if the case is dismissed in court or the offender finally sentenced. For example, if at the end of their investigations the police suspect manslaughter, then the case will be recorded as manslaughter in the Police Crime Statistics, even if a court ultimately hands down a sentence for assault resulting in death or even lets the suspect go free. The Police Crime Statistics are not corrected after the final ruling of the court. Additionally, they also distort timing as crimes are included when detected, not when committed. In most cases this is unimpor-

1 Registry offices provide additional demographic data once a death notice is issued.

2 According to the ICD-10 categories X85-Y09. 
tant as most crimes are detected quickly. Where there is a long time lag, however, it is easy to imagine that this can lead to major distortions, at least for rare crimes. ${ }^{3}$

The Police Crime Statistics can nonetheless be used to gain a general overview of the frequency of (reported) child homicide in Germany (see Figure 9.1). As the official data show, contradicting the picture often painted in public, the number of homicides involving children under six in Germany is, at least in terms of reported crime, on a downward trend with slight fluctuation since 1997.

\section{Fig 9.1 Victims of intentional, completed homicide under 6 years of age in Germany, 1997-2010 (source: Police Crime Statistics; own calculation). ${ }^{4}$}

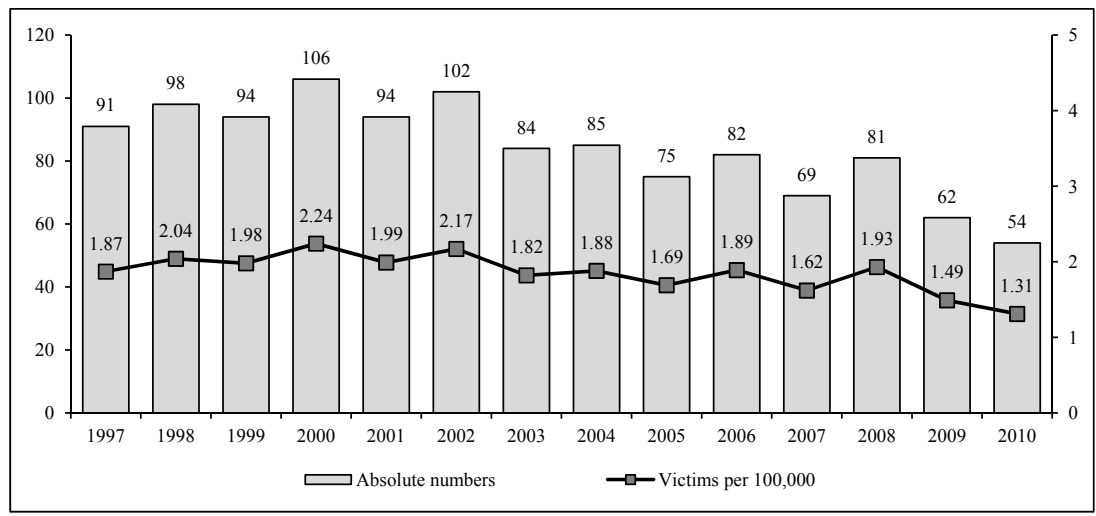

3 An example that attracted strong media interest is the Brieskow-Finkenheerd case in Germany where a woman had nine children between 1988 and 1998 and killed them all at birth. The crimes only came to light in 2005 and were not included in the Police Crime Statistics until 2006 (after the investigations were completed).

4 The following crimes are aggregated in the chart: Murder, § 211 German Criminal Code StGB; Manslaughter, $\S 212,213$ StGB; killing on demand, § 216 StGB; Infanticide, $\S 217$ StGB (which existed until 1998, relating to the killing by the mother of an illegitimate child at birth; since the abolition of this offence, neonaticides come under the general provisions of the Criminal Code relating to crimes involving assault resulting in death, manslaughter or murder);assault resulting in death, $\S 227$ StGB; Sexual assault and rape resulting in death, § 178 StGB; Sexual child abuse resulting in death, $\S 176 \mathrm{~b}$ StGB. 
Academic research on child homicide in Germany has so far been restricted to regional studies, studies relating to specific categories of crime, and studies mainly addressing selected aspects of crimes and their circumstances (Bozankaya 2010, Hömberg 2011, Hempel 2013, Schlang 2006, Schmidt et al. 1996, Schläfke et al. 2003, Trube-Becker 1982, Raic 1997, Vock 1999, Vock/Meinel 2000, Vock/Trauth 1999). Internationally, too, although there is abundant research, most of it merely sheds light on a subset of cases (e.g. Friedman et al. 2005, Resnick 1970), covers only a small number of cases (e.g. Bourget/Gagné 2002, Bourget/Gagné 2005) or relates to far older age groups, with the result that only isolated conclusions can be drawn about young child victims (e.g. Bijleveld/Smit 2006). Some reviews have been published which pointed out some general trends but also a included great number of inconsistent findings (Bourget/Grace/ Whitehurst, Friedman/McCue/Resnick 2005, Friedman/Resnick, 2007 and 2009, Porter/Gavin 2010).

Concerning the victims age, the existing studies show consistent trends, apparent differences are based on age group variations, especially on whether or not the neonaticides are included. A child's risk of being killed is clearly highest during the first year of life (Mariano/Chan/Myers 2014; Paulozzi/Sells 2002; Vock/Trauth 1999; Raic 1997), then rapidly decreases and is only slightly rising from the early teens (Mariano/Chan/Myers 2014; Strang 1996). No major differences regarding the victim's sex were found in larger studies (Vogt/Block 2005), studies with smaller samples show a slightly higher rate of male victims (Vock 1999; Vanamo/Kauppi/ Karkola et al. 2001).

Offenders of child homicide cases are most likely persons of the closest social environment of the children, usually parents or stepparents (Porter/ Gavin 2010; Flynn/Windfuhr/Shaw 2009), although the proportion varies, probably again due to different sample compositions. When it comes to the offenders' sex, results are not that consistent, except for the neonaticide cases, which are mostly committed by the biological mothers alone (Beyer/McAuliffe Mack/Shelton 2008; Herman-Giddens/Smith/Carlson/ Butts 2003; Vanamo/Kauppi/Karkola et al. 2001). A german study on intra-familial child homicide cases $^{5}$ for the years 1985-1989 showed a significantly higher rate of male offenders (Schlang 2006), just like Strang (1996) for Australian child homicide cases between 1989 and 1993 on

5 Victim's age: $<18$ years, without neonaticide cases. 
children under 15 years of age. For the subsample of 58 lethal child maltreatment cases, Vock et al. (1999) also found a dominance of male offenders: In each about $30 \%$ fathers and mothers were perpetrators, but in an additional group of $16 \%$, the biological mothers new partner had killed the child. About $25 \%$ of the cases of this sample were committed by both parents together. In summary to this point it can be said that mothers as offenders of child homicide are overrepresented for newborns and very young children, whilst with increasing victim age, male perpetrators become more important.

In the existing studies, results concerning a higher risk for children with stepparents ("cinderella effect") are also inconsistent: Daly/Wilson (1988, 2001, 2005) as well as Harris/Hilton/Rice/Eke (2007) describe a higher risk for infanticide for children with stepparents in analyses of British and Canadian data and attribute their findings to evolutionary mechanisms. Weekes-Shakelford/Shakelford (2004) confirmed these findings for the USA regarding biological mothers and stepmothers, whereas Brookman/ Nolan $(2006)^{6}$ could only show effects for stepfathers, but not for stepmothers. Stiffman/Schnitzer/Adam et al. (2002) analysed data from the Missouri Child Fatality Review Panel System ${ }^{7}$ and could show a higher risk for children living in the same household with one or more non-relative male/s for lethal maltreatment compared to children living with both biological parents. These observations are contradictory to the ones of Schnitzer/Ewigman (2005), who also looked at data from Missouri ${ }^{8}$ and could identify a dominance of male offenders $(71 \%)$, but not a considerably higher risk for children living with stepparents. Swedish studies ${ }^{9}$ did also not find a connection between being a stepparent and an increased risk of child homicide.

Available information on the offender's socioeconomic backgrounds varies widely. For Germany, Raic (1997) could show a higher proportion of middle-/upper class- perpetrators for the subcategory of extended suicides. In a review from 2005, Hatters Friedman/McCue Horwitz/Resnick described a medium-low socioeconomic background for neonaticide of-

6 Investigation of 298 cases in England and Wales between 1995 and 2002.

7 1992-1992, age of victims $<5$ years.

8149 cases of lethal maltreatment cases committed by a parent or caregiver (1992-1999).

9 Termrin/Buchmayer/Enquis 2000 (1975-1999); Temrin/Nordlund/Sterner 2004 (1965-1999). 
fenders, whereas perpetrators of homicides of elder children were found to being poor and socially isolated. Hässler/Bomke/Schäffler (2003), who analysed 56 psychiatric reports from the Psychiatric Department of the University of Rostock (Germany) for the years 1980-2000 on the other hand associate most offenders $(59.6 \%)$ to social middle class, $32.7 \%$ to lower social class and $7.7 \%$ to the upper class.

The majority of studies dealing with backgrounds and possible triggers for child homicide discuss psychiatric illness of the parents, which probably refers to the fact, that quite a number of authors have a psychological/ psychiatric background. For neonaticides the knowledge to these questions is inconsistent. Oberman (2003), who looked at cases from Chicago between 1870 and 1930, found that a large number of offenders suffered from psychiatric diseases. Resnick (1970) as well as Schläfke/Galleck/ Höppner/Hässler (2003) describe a rather low proportion of psychical problems for these perpetrators. For the age-group of $231<18$ year-old victims, Schlang (2006) describes mental disorders for $52.7 \%$ of the female and for $29.5 \%$ of the male offenders, with personality and behaviour disorders being most frequently (34\%), followed by disorders caused by psychotropic substances, of schizophrenic or affective kind (each about $15 \%)$.

Overall homicide of children in the age group 0-5 years is far from being fully understood. Some general lines have been detected but knowledge regarding the exact circumstances, risk factors and determinants of homicides is still quite limited. For this reason, the Child Homicide project has been conducted at the Criminological Research Institute of Lower Saxony since 2007.

\subsection{The Child Homicide project ${ }^{10}$}

The project involved an exhaustive survey of all homicides involving children under 6 years of age in Germany for the period 1997-2006 based on analysis of the relevant court files. The state bureaus of criminal investigation were first asked for a list of relevant reference numbers. These were then presented to the respective state prosecution services, who were asked to send the case files to the Criminological Research Institute of

10 The project received funding from the Fritz Thyssen Foundation. 
Lower Saxony. The case files were analysed by trained coding staff using paper and pencil to compile comprehensive information for each victim on the biological and (if applicable) social parents and any other individuals accused. An approximately one-page case outline was additionally written out for each case, presenting the case history from when the case first came to police notice. These case outlines frequently proved useful during later analysis as they helped bringing each case to mind beyond the basic facts. Finally, the compiled data were entered in SPSS ready for further analysis.

As all further analysis is based on the criminal investigation files, it is important at this point to note the special characteristics and limitations that apply to the study. One problem was the fact that some files were visibly incomplete; relatively frequently, for example, psychological/psychiatric reports or records on the main court hearing were missing. In most cases the absence of individual parts of a file was not really a problem because the same information was referred to elsewhere in the file, for example in the court decision; in other cases, however, missing information could not be made up in this way and remained missing from the entered data. In any analysis of criminal investigation files, it is important to remember that the focus is on identifying the offender and criminal appraisal of their actions, and not on reconstructing the case to the last detail. Information only makes it into the file if the investigating authorities consider it important to the criminal prosecution. Also, the statements made by all parties come in the context of a given (procedural) role (e.g. as witness or accused) and may therefore be coloured by self-interest. All these aspects must be taken into account when going on to analyse information from criminal investigation files.

\subsection{Findings: All Cases}

A total of 627 files were analysed. These included 507 relevant cases ${ }^{11}$ with 535 victims and 354 offenders. Most victims were killed in their first year (69.2 percent), which mainly reflects the large number of neonati-

11 The remaining files related, for example, to attempted homicides that children survived, other age groups or other crimes. 
cides. ${ }^{12}$ Even without this category, however, still no less than 30 percent of the victims were killed in their first year, 10.6 percent in their second, 6.8 percent in their third, 6.6 percent in their fourth, 3.3 percent in their fifth and 3.6 percent in their sixth year. The risk of children in the studied age group for becoming a victim of homicide is thus by far the highest in the first year, with a clear concentration in the first 24 hours after birth.

\subsubsection{Necessity of classification into case groups}

For adequate analysis of the great diversity of cases involved, different categories based on classifications used in the literature (Resnick 1969, d'Orbán 1979, Scott 1973) were developed. The classifications were adapted and modified several times in the course of the project. At the beginning, for example, there was a "revenge killing" category as found in the literature (Resnick 1969, d'Orbán 1979). On closer examination of our sample, however, there were no cases in this category and the category was therefore dropped. The classification ultimately chosen combines characteristics of the homicides, the delinquents and the victims.

\section{Neonaticide}

This case group comprises 199 victims (37.2 percent). Victims were almost exclusively killed by the biological mother during or immediately after birth; only in very exceptional cases assistance was provided by another person. 'Typical cases' are those in which the mother, immediately after giving birth without assistance, left the infant unprovided or killed it mostly by suffocating - without conscious premeditation. Almost all such cases involved an unwanted pregnancy where labour commenced unexpectedly. There were very large differences as to whether and how a pregnancy was denied and/or concealed. With regard to concealing the killing, the spectrum ranges from no attempt at concealment and 'poor' hiding places for the body such as the mother's own wardrobe to elaborate elimination of traces.

12 Neonaticide is the killing of a child within 24 hours of birth, in the great majority of cases by the mother alone, usually after a concealed and/or denied pregnancy. 


\section{Maltreatment}

The death by maltreatment case group ( $\mathrm{n}=137$ or 25.6 percent) combines various forms of maltreatment resulting in death: Blunt force (with/without an object), shaking, and in rare cases substance administration. The duration and intensity of maltreatment varied considerably, from one-off acts in the heat of the moment (often the case with fatal shaking of the infant) through to longer-term maltreatment only leading to the death of the infant after some time or in combination with other injuries.

\section{Extended suicide}

The extended suicide case group includes both suicides and attempted suicides. The category comprises 69 victims in total (12.9 percent). In cases of completed extended suicide there is usually very little information about the perpetrator as the criminal prosecution was closed immediately. Not infrequently, before both suicides and attempted suicides it was already known that the perpetrator had major psychological problems of a depressive nature, often in connection with a family crisis. In most cases of attempted extended suicides, the perpetrator's own suicide was not completed because of an extraneous disturbance or rescue; in other cases the offender abandoned the plan to commit suicide after killing the child. There are also variations with regard to the fatality risk of the suicide attempts. 'True' extended suicides predominated, where the offenders' usual motive was to take the child with them so that it would not be left behind alone. The remaining cases were suicide attempts where the child was more or less coincidentally present or the child disturbed a suicide attempt and was killed in that connection. In a few cases, other individuals were killed immediately before the suicide or attempted suicide, most frequently the other parent and/or other children.

\section{Mental illness}

In this group those cases were included ( $\mathrm{n}=33 ; 6.2$ percent) where severe mental illness such as postpartum depression, psychosis or an acute schizophrenic episode was the direct trigger of the killing, regardless of other case characteristics. Cases with a suicidal component on the other 
hand were always assigned to the extended suicide category regardless of any mental illness. The case group contains numerous variations at many different levels: The duration of the illness ranges from a few weeks to many years, some illnesses were treated, while others were not even known to people close to the perpetrator. In only very few cases, the treating physician or family had the idea that the illness could possibly be a danger to others; in most cases, the offender's direct environment had not the slightest suspicion of the actual risk potential.

\section{Purposeful homicide}

This group includes all cases $(n=32 ; 6.0$ percent $)$ where the perpetrator purposefully carried out the homicide with clear intent to kill, by ways or means relatively certain of killing, that do not come into any of the other categories (such as extended suicide or mental illness). In some cases it was hard to distinguish cases in this group from maltreatment case group. Many of the cases were homicides committed in the context of separation problems and custody disputes, mostly with a range of motives such as not wanting to give up the child or begrudging it the partner compounded with altruistic components (such as saving the child from a presumed hard or sad future). This category also includes cases, however, where a child was killed because it was 'in the way' and the perpetrator wanted to 'get rid' of it.

\section{Neglect}

This category subsumes cases ( $\mathrm{n}=20 ; 3.7$ percent) where children died because they were not supplied with sufficient food and/or liquids or because they were denied necessary medical treatment. These are cases of pure neglect; the extremely rare cases in which neglect was accompanied by physical maltreatment of the child were classified as maltreatment.

Natural death/accident

With regard to victims in this category, investigations were initially carried out for suspected homicide, however in the course of investigations it 
emerged that the children died a natural ${ }^{13}$ or accidental ${ }^{14}$ death. This category consists of 29 victims (5.4 percent).

\section{Unclear sudden infant death syndrome (SIDS)}

With the cases in this group ( $\mathrm{n}=8 ; 1.5$ percent), there was suspicion of homicide but the cause of death could not be identified with certainty (unlike the natural death/accident category). Sudden infant death syndrome and, for example, intentional suffocating are both possible in such cases.

\section{Other}

A small number of cases $(n=8 ; 1.5$ percent) could not meaningfully be assigned to any of the other categories but did not have any salient common features and hence were grouped in an 'other' category. An example is cases where the child was a chance victim. ${ }^{15}$

In the last three case groups, the children did not (with certainty) die as a result of intentional homicide, but are retained as victims in the overall sample for analysis as the starting point of our study was the classification of cases at the end of police investigations. This circumstance is taken into account descriptively later on, however, when focusing on the various case groups.

\subsubsection{Perpetrators}

The term 'perpetrator/offender' is reserved in the project for persons who were issued with a final sentence, persons acquitted on account of exemption from criminal responsibility, and persons who killed a child in an extended suicide. Cases were included in the study when the police classifi-

13 Such as following myocarditis or undetected diabetes.

14 For example because the child fatally injured itself falling out of bed or died in a domestic fire it inadvertently started itself.

15 For example in a gas explosion or in a road accident deliberately caused by a driver travelling on the wrong side. 
cation of the incident was intentional homicide. ${ }^{16}$ Sometimes the conviction was for a less severe crime (usually because it was not possible to establish intent to kill). Such cases usually ended in a conviction for maltreatment of persons under the offender's care, assault, or homicide by negligence. The analysis included 354 persons who satisfied this definition of a perpetrator. The number of perpetrators is thus significantly smaller than the number of victims, mostly because of the large number of newborns found dead where the perpetrator could not be identified. In other cases, however, a suspicion was unable to be confirmed in a way that provided sufficient grounds for prosecution or conviction, resulting in dropping of charges or acquittal. From a victimological point of view, however, the circumstances in some such cases justify a classification as victims. ${ }^{17}$

\section{Fig. 9.2 Relationship between delinquent and victim (in percent)}

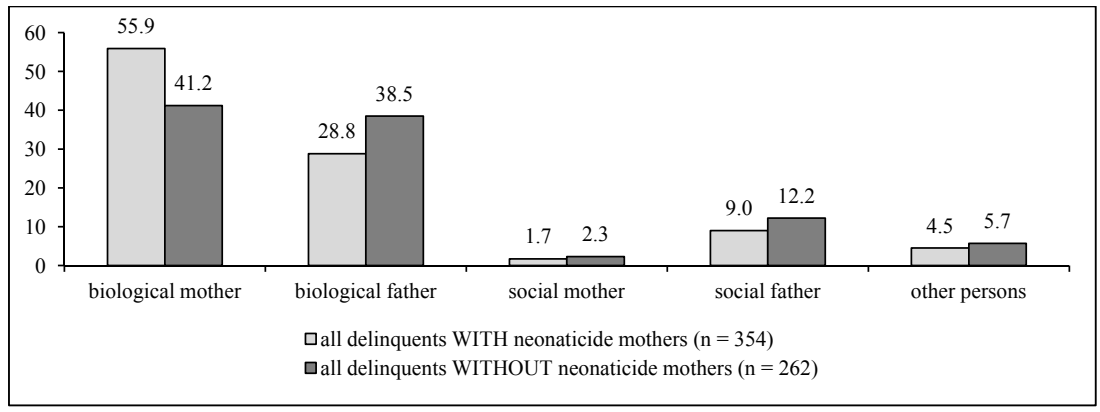

With rare exceptions, the perpetrators came from the children's immediate surroundings ${ }^{18}$ and the great majority were the biological and/or social parents ${ }^{19}$; in rare cases, the perpetrators were 'other persons' such as

16 See footnote 4.

17 As in cases where it was clear that one of the parents must have committed the homicide but the court was unable to establish which one and had to acquit both as a result. There were also neonaticide cases where it was not possible to determine with certainty whether the child had been stillborn or killed by the mother.

18 One such exception was a driver travelling on the wrong side of the road who deliberately collided with an oncoming vehicle.

19 A social parent is partner to a natural parent, such as the mother's new boyfriend. To count as social 'parents' such individuals must at least contribute towards providing for the child and take responsibility in childcare. 
grandparents and roommates. Looking at all perpetrators, biological mothers visibly dominate, but this effect almost disappears after deducting the large number of biological mothers who were perpetrators of neonaticides (see Figure 9.2).

\subsection{Findings by case groups}

In view of the large differences between the various case groups, selected findings of the study are presented separately by category in the following.

\subsubsection{Neonaticide}

The neonaticide case group is the group with the largest number of victims, including numerous newborns found dead for whom no perpetrator could be identified despite in some cases with very intensive investigations. As this case group included large differences despite its basic homogeneity, four subcategories were defined:

- 'Typical' neonaticide ( $\mathrm{n}=96 ; 48.2$ percent): In these cases, the biological mother killed the infant immediately at the time of birth, either actively or by not providing for it. In such cases the pregnancy was denied/concealed, birth and the homicide were unassisted.

- 'Atypical' neonaticide ( $\mathrm{n}=13 ; 6.5$ percent): These cases differ from typical neonaticides on at least one count. In some cases the victim was born in hospital and killed at home a few days later, or the mother had assistance with the birth. Despite these distinguishing features, the remaining circumstances, and particularly the denied/concealed pregnancy, justify classification in the neonaticides group.

- Unclear neonaticide ( $n=36 ; 18.1$ percent): It was not possible to establish sufficient proof but classification as neonaticide was justified from a victimological standpoint. ${ }^{20}$

- Unknown dead newborn ( $\mathrm{n}=54 ; 27.1$ percent): In such cases, a newborn is found dead that is highly probable to be victim of a homicide but it was not possible to identify the perpetrator.

20 Examples include where it was not possible to prove a specific homicidal act with final certainty. 
The perpetrators had an average age of 24 years at the time of the homicide; approximately 16 percent were under 18 , just under 21 percent were between 18 and 20, and the largest group were women between 21 and 29. Over 50 percent of the perpetrators already had biological children at the time of the neonaticide, although only eight women lived with these children in a common household at that time. Eight women had put up one or more children for adoption before the neonaticide. ${ }^{21}$ The case group included seven cases with two victims and three cases with three victims. As is to be expected, the victims showed no gender bias: 50 percent were female and 48 percent male. ${ }^{22}$ None of the infants was disabled. Of the infants for which the pregnancy term could be determined, eight percent were premature. ${ }^{23}$ This is not significantly higher than in the general population. ${ }^{24}$

Almost all women underwent psychological/psychiatric examination in the course of the investigations; mental health problems were found for 42 women at the time of the offense and for 29 in the past. The spectrum of findings was very broad, although acute stress reactions and fearfulavoidant personality traits were frequent. Only very rarely did the perpetrators engage in alcohol or in medical or narcotic drug abuse with rates of less than 5 percent for each. Almost all women had previously denied and/or concealed the pregnancy. In the cases analysed, it was not possible to observe the clear distinction often made in the literature between denial and concealment; instead there were a wide range of hybrid forms and blurred transitions. Pregnancy denial/concealment was always one of the key reasons for the neonaticide. In most cases the women were surprised by the birth and were unable to deal with the situation in a premeditated and appropriate manner, even in cases where they had given thought in advance to what they would do with the child once born. Other aspects, such as fear of being left by a partner or of being unable to cope with the new situation in life, as with the influence of alcohol or drugs, only acted in favour of the neonaticide in isolated cases. Interestingly, even women who

21 Three women had already put up two children for adoption and one women three children.

22 In the remaining 2 percent of cases, the gender could no longer be determined.

23 For the purposes of the project, premature births were defined as prior to the $37^{\text {th }}$ week of pregnancy.

24 In 2007, for example, 7.1 percent of births in Germany were premature (European Foundation for the care of newborn infants 2010). 
had chosen other courses of action in past unwanted pregnancies ${ }^{25}$ were evidently unable to act this way again when it came to the victim infant, and were also unable to explain why they couldn't.

The dominant act of homicide, at about 23 percent, was suffocation, including both active forms such as smothering with a pillow and passive forms such as wrapping in a blanket. The second most frequent, at about 11 percent, was failure to provide for the newborn (which then died of hypothermia or lack of nutrition) or active violence (throttling/choking/strangulation). About 7 percent of infants drowned ${ }^{26}$, and only low single digit percentages were found for stabbing, blunt force and throwing of the child out of the window. In about 37 percent of the cases the precise course of events remained unclear or could no longer be reconstructed more precisely, largely due to the discoveries of unknown dead newborns where the passage of time meant the cause of death could no longer be established with certainty.

In a sense it is possible to say that in most cases the denial of the pregnancy persisted beyond the birth, and that the women acted more in an attempt to "bring the situation to an end" without proceeding in a planned or premeditated way. This can be concluded especially in the cases where the dead body was later 'concealed' somewhere in the mothers home, even though this made a detection highly likely.

The very large majority of perpetrators in the neonaticides case group was convicted of manslaughter ( $\$ 212$ of the German Criminal Code $\mathrm{StGB})$ or a less serious case of manslaughter ( $\$ 213 \mathrm{StGB})$, with convictions being made significantly more frequently for action than for omission (see Figure 9.3).

Sentencing was dominated by unsuspended prison or juvenile prison sentences (43 resp.14 cases), followed in second play by suspended prison or juvenile prison sentences (18 resp.15 cases), meaning that in total 56 of 92 women, or some 60 percent, received an unsuspended sentence. The severity of the unsuspended sentences was mostly in the lower to middle range (2-6 years of prison), although no less than seven women were sentenced to six to ten years and another six to over ten years imprisonment.

25 Besides the eight women who put up children for adoption, it is known in respect of 20 women that they had one or more abortions behind them.

26 This included only very isolated cases of active drowning by the mother. 
Fig. 9.3 Neonaticide: Final judgement-Distinction by offenses (in percent; *Value is for action and omission). ${ }^{27}$

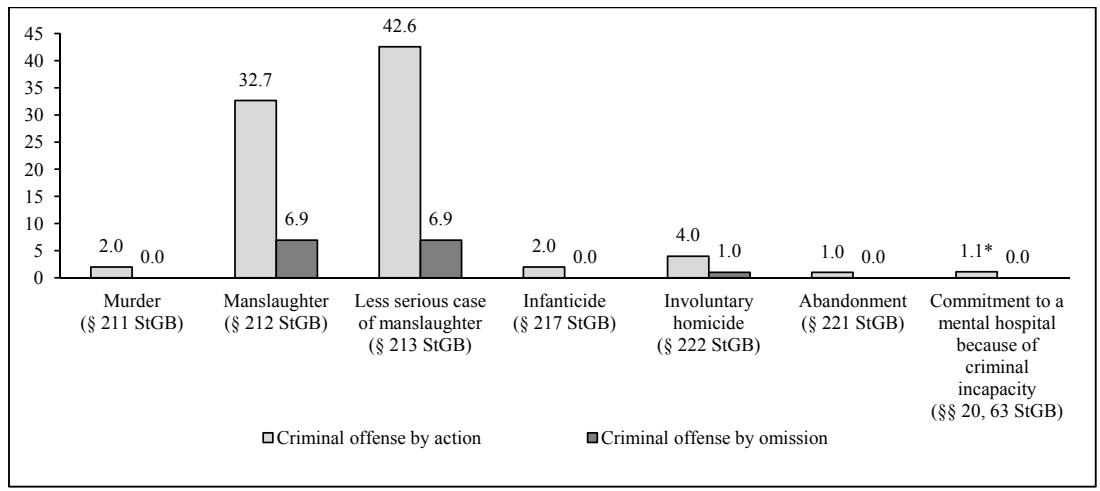

\subsubsection{Maltreatment}

Given the large differences within it, the death by maltreatment category was likewise subdivided, although in some cases it was hard to distinguish based on the files between, for example, cases of single and cases of multiple maltreatment. The figures can therefore only serve as guidance to the general size of the subcategories. Cases can be divided into single instances of maltreatment ( $\mathrm{n}=37 ; 27$ percent), multiple instances over a period of time ( $\mathrm{n}=49 ; 35.8$ percent), and cases where infants died following a shaking trauma ( $\mathrm{n}=26 ; 19$ percent), as the latter group of cases are particularly important from a forensic medicine point of view. There were also cases of maltreatment where it was not possible to establish with legal certainty whether, and most of all by whom, the children had been maltreated $(\mathrm{n}=17 ; 12.4$ percent) or shaken $(\mathrm{n}=8 ; 5.8$ percent) but where a victimological point of view justified a classification as victims.

Among the 126 perpetrators, the biological mothers and fathers were represented in roughly equal numbers, at 34.4 percent, resp. 35.2 percent. The proportion of social fathers as perpetrators was significantly higher

$27 \S 217$ StGB existed until 1998, relating to the killing by the mother of an illegitimate child at birth. Since the abolition of this offence, neonaticides come under the general provisions of the Criminal Code relating to crimes involving assault resulting in death, manslaughter or murder. 
than in any other case group, at 21.6 percent. Other perpetrators such as social mothers or friends/acquaintances of the parents were found only in very isolated cases. More than a quarter of perpetrators had themselves been victims of abuse in childhood and there were at least clear indications of this having been the case for a further 5.6 percent. ${ }^{28} 78$ percent of perpetrators in this case group underwent psychological/psychiatric assessment in the course of criminal prosecution, with just under 45 percent showing problems in the past and 36 percent at the time of the offense. The most frequent problems were substance abuse ${ }^{29}$ ( 28 resp. 10.4 percent) and personality disorders (5.6 resp. 11.2 percent). Only rarely were there additionally other or combined mental problems/disorders such as depression, adjustment disorders or Münchhausen-by-proxy syndrome.

This case group included a very wide range of acts of homicide, although the children most frequently died of blunt force/maltreatment ${ }^{30}$ (44.5 percent) or shaking (26.3 percent). Other forms of homicide such as suffocating, poisoning, strangulation or drowning were found only in isolated cases. In 13.1 percent of cases the act of homicide remained unclear, with multiple possibilities coming into question and no way of being certain which was ultimately fatal. The homicide was usually triggered in this case group by a situation where the perpetrator was unable to cope with the child, usually coupled with a general inability to cope with their situation as a whole or with specific circumstances. In many cases the child screamed or cried before the incident for an unspecific reason and - in some cases despite serious and persistent attempts on the part of the perpetrator - was unable to be calmed. In such cases, the perpetrators lost their nerve and committed the homicide mostly in the heat of the moment so that the child would at last be 'quiet'. With just under a fifth of perpetrators, the homicide was presumably abetted by disinhibition and/or heightened aggression due to alcohol or drugs. In some cases, the fatal maltreatment was the expression of what the perpetrator considered to be "teaching

28 Here especially, absence of information should not be equated with absence of maltreatment in the perpetrator's childhood. Instead, it is probable that such experience of maltreatment is not asked about in the course of investigations if the investigators consider it to have had no influence on the offense in question.

29 This subsumes abuse of various substances including alcohol, medical drugs and narcotic drugs, and long-term excessive as well as abusive consumption.

30 For example striking with the hand, slamming of the head against an object or against a wall, or scalding. This case group showed particularly large variation in the nature and intensity of the homicidal acts involved. 
a lesson', often with pent-up aggression released against the child for some trivial reason. In some such cases the maltreatment was extreme.

With regard to the age of victims, the high risk period clearly is the first six months of a child's life, a period in which 54 percent of victims in this case group were killed. The risk level then decreases significantly and is subject to only minor variation thereafter. The maltreatment group is the only case group to show marked differences in victim gender, with 65 percent $(n=89)$ of victims being male and 35 percent $(n=48)$ female. The reasons for this heightened risk are unclear so far and deserver further attention.

Maltreatment perpetrators were most frequently (50 percent) convicted for assault resulting in death ( $\$ 227 \mathrm{StGB}$ ), with significantly more accusations of criminal offense by action than by omission. In 17.5 percent of cases the final conviction was for manslaughter ( $\$ 212 \mathrm{StGB})$ and in 2.4 percent for a less serious case of manslaughter ( $\$ 213 \mathrm{StGB}) .11 .2$ percent were convicted for murder ( $\$ 211$ StGB), 10.3 percent for involuntary homicide ( $\$ 222$ StGB), 6.4 percent for maltreatment of charges $(\S 225$ $\mathrm{StGB}$ ) and 2.4 percent for (serious) assault (§ $224 \mathrm{StGB}$ ) (see Figure 9.4).

\section{Fig. 9.4 Maltreatment: Final judgment-Distinction after offenses (in percent)}

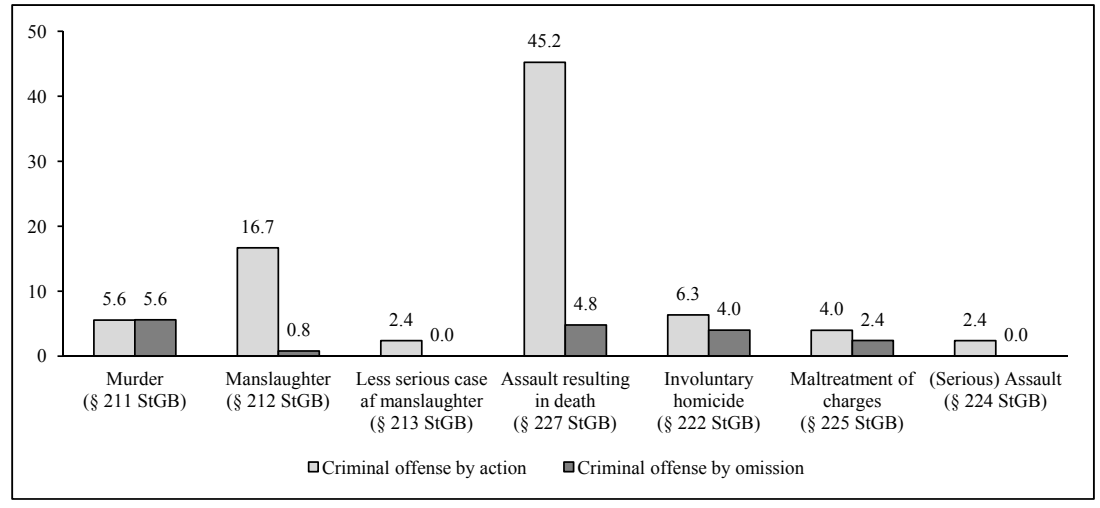

In most cases, the sentences handed down were unsuspended prison or juvenile prison sentences (68 resp.10.4 percent), more rarely suspended prison or juvenile sentences (13.6 resp. 4 percent). Only in isolated cases was a prison sentence combined with accommodation in a psychiatric hospital or drug rehabilitation centre, or a fine was imposed. With regard to 
sentencing severity, unsuspended prison sentences tended to be at the severe end of the range (more than six years); in 19.1 percent of cases the prison sentence was between four and six years and in 20.2 percent of cases between two and four years. The unsuspended juvenile prison sentences most frequently - in six out of 13 cases - consisted of a severe sentence of between six and ten years ${ }^{31}$; juvenile prison sentences of four to six years were handed down in three cases and juvenile prison sentences of between two and four years in four cases.

\subsubsection{Extended suicide}

This case group includes a conspicuously large number of cases with multiple victims: 11 cases featured two child victims out of the case group, making up 31.9 percent of this small subcategory. There were more completed than attempted suicides. Of the 53 perpetrators in the case group, 22 survived and 31 completed the suicide. The offenders were almost always the children's biological parents ${ }^{32}$, with fathers slightly outnumbering mothers by 27 to 23 . With regard to the age of perpetrators, the 30-40year old offenders dominated with just over 56 percent, just under 27 percent $(n=4)$ were over 40 and only a little over 15 percent $(n=8)$ were between 21 and 29 years old. Only one perpetrator was between 18 and 21 years old and none was under 18. Offenders in this case group were thus significantly older on average than in the other categories. Almost all surviving perpetrators underwent psychological/psychiatric assessment and for 19 it is known that they had mental problems or even mental disorders at the time of the attempt; eight had a depressive disorder and four a personality disorder. Other disorders ${ }^{33}$ were present only in individual cases. Only very few perpetrators in this case group had a substance abuse problem and only three had problems of this kind in a period of up to one year before the suicide or suicide attempt.

The triggering event in the extended suicide case group was usually a separation conflict, where perpetrators were unable to cope with an impending or actual separation and wanted to take their own life for that reason. There were various reasons why the offenders wanted to take their

31 The maximum juvenile sentence in Germany is ten years.

32 A social father was the perpetrator in two cases and a friend of the family in one.

33 Such as bipolar disorder, PTSD or an adjustment disorder. 
children with them when they died: In some cases there were altruistic motives from the perspective of the perpetrator, who for example did not want the child to be 'left behind' or grow up without an intact family; in other cases they did not want the other partner to 'get' the child; and in isolated cases there were other motives such as heavy burden of debt, and by committing the extended suicide the perpetrator wanted to save his or her family 'suffering and shame'. In some cases the suicide or suicide attempt came in connection with a mental disorder suffered by the perpetrator. There was no notable bias with regard to the age or gender of victims.

The act of homicide in this case group was often stabbing or other forms of knife injury, with over 25 percent of victims dying in this way. Just under 19 percent of victims were throttled/choked/strangled and just under 12 percent suffocated. The same number of victims was pushed over a bridge or run over by a train. Other acts of homicide tended to be found in only isolated cases (see Figure 9.5).

Fig. 9.5 Extended suicide: Acts of homicide (in percent).

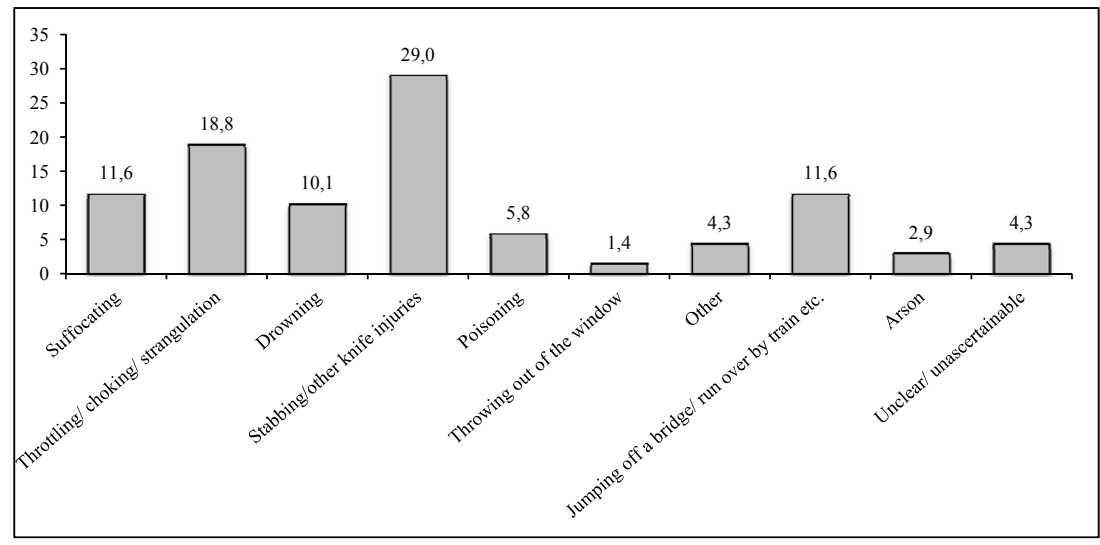

Of the 22 surviving perpetrators, ten were subsequently convicted of murder ( $§ 211$ StGB), eight of manslaughter ( $\$ 212$ StGB) and five of less severe cases of manslaughter ( $\$ 213 \mathrm{StGB})$. By far the majority of offenders received an unsuspended prison sentence; only one was given a suspended sentence and three were found to be exempt from criminal responsibility and were ordered to be placed in a psychiatric hospital. No juvenile sentences were handed down. With regard to sentencing severity, long and very long prison sentences dominated in this case group with nearly two- 
thirds of perpetrators receiving prison sentences of over six years and six perpetrators being convicted to prison sentences of over ten years; five were given life sentences.

\subsubsection{Mental illness}

This category includes 33 victims from the sample who were killed by 24 perpetrators, all of whom were the biological parents. A conspicuous feature is that a significantly larger number of offenders were mothers than fathers (18 mothers, six fathers). There were no very young or very old perpetrators, with all offenders falling in the 21-40year-old age group. All perpetrators in this case group underwent psychological/psychiatric assessment as part of the criminal prosecution. For 23 of the 24 perpetrators it is known that they were mentally ill before the homicide, with by far the most frequent mental illnesses being psychoses, schizophrenia or other delusional disorders; only four offenders had previously been depressive, and the remainder had personality disorders or personality accentuations. In line with the definition of the case group, at the time of the homicide all perpetrators had a mental illness under the influence of which the homicide was committed. As with past mental illnesses, the dominant form of illness consisted of psychotic disorders, in one case postpartum. Five offenders had various forms of depression and there were isolated cases of adjustment disorder, stress reaction, PTSD and other disorders. With six perpetrators, the mental illness was comorbid with a personality disorder, either from the fearful-avoidant or dramatic-emotional cluster.

In accordance with the definition of the case group, the homicide was triggered in all cases by the perpetrator's mental illness, with varying 'reasons' for the homicides in line with the various underlying disorders. Psychotic/schizophrenic/delusional offenders, for example, were paranoid or believed killing the child was the only way to protect it from other persons or from the devil. Depressive perpetrators mostly killed the child out of perceived inability to cope. Only rarely was the mental illness accompanied by other aspects that abetted the homicide such as an acute separation situation or alcohol/drug influence.

The most frequent act of homicide in the mental illness case group was suffocating $(n=12)$. Six children were stabbed to death, four drowned, and four others died as a result of blunt force. Only in isolated cases were the children strangled, poisoned or thrown out of a window. A strong bias is 
visible with regard to victim age in this case group, with 14 of the 33 victims killed at an age of between one day and three months; the victim ages are distributed fairly evenly over the remaining age groups.

A majority $(\mathrm{n}=20)$ of perpetrators were found to be exempt from criminal responsibility under $\S 20$ of the German Criminal Code StGB (criminal incapacity) and ordered to be placed in a psychiatric hospital subject to satisfaction of the requirements set out in $\S 63 \mathrm{StGB} .{ }^{34}$ The remaining perpetrators were merely found to have diminished criminal incapacity according to $\S 21 \mathrm{StGB}$; two of these were convicted of murder $(\S 211$ StGB), two of a less severe case of manslaughter ( $\$ 213 \mathrm{StGB}$ ), and two of assault resulting in death ( $\$ 227 \mathrm{StGB})$. No perpetrators in this case group were given a juvenile prison sentence; two were handed down a suspended prison sentence and two an unsuspended prison sentence; for one offender, in addition to the prison sentence, placement in a psychiatric hospital was ordered according to $\S 63$ of the Criminal Code. Seventeen perpetrators were solely ordered to be placed in a psychiatric hospital; for three of these the sentence was suspended.

\subsubsection{Purposeful homicide}

This case group comprises 32 victims, including four cases in which two victims were killed and one case with three victims. With regard to age, this small subcategory again shows a heightened risk for children aged one day to three months, an age group in which eight victims were killed. Of the 27 perpetrators, 16 were the biological fathers and eight were the biological mothers of the children. The remaining offenders were a social father and friends of the mother. Most perpetrators were in the 21-29yearold age group $(n=10)$ or the $30-40$ year-old age group $(n=11)$; only in rare cases were they young adults, i.e. between 18 and $20(n=2)$, or over 40 years old $(n=4) .23$ of the offenders underwent psychological/psychiatric assessment in the course of prosecution ${ }^{35}$ and it emerged that 13 already

34 Only in one case did the court refuse to make such an order; this was determined on commencement of the main hearings as the court did not consider the perpetrator a danger to the public as $\S 63 \mathrm{StGB}$ requires.

35 In the remaining cases, either the offenders refused to be assessed and asserted their right to remain silent in the main hearings, or, as in one case, the perpetrator was not convicted by a German criminal court, hence no information on any as- 
have had mental problems or disorders prior to the homicide, in the form of drug abuse/addiction $(n=5)$, personality disorders $(n=4)$ and combined mental disorders $(\mathrm{n}=2)$. In two cases it was at least surmised that the perpetrator have had a mental illness prior to the homicide. ${ }^{36}$ For 13 perpetrators, a mental illness/problem was diagnosed at the time of the homicide, mostly a personality disorder $(n=7)$ or personality accentuation $(n=4)$; one offender had a disorder belonging to the adjustment disorder/stress reaction/PTSD category and one had a psychotic disorder.

The dominant act of homicide in this case group was once again suffocation $(n=13)$. Six victims were stabbed to death and six drowned; only in individual cases were children strangled or died as a result of blunt force, following a fall from a window or a deliberately started fire. In two cases the act of homicide remained unclear - in one the body was not found and in the second the cause of death could no longer be ascertained due to the passage of time. There were essentially two particularly frequent triggers for the homicide: One was an acute or ongoing separation conflict. In other cases the children were perceived as a 'burden' or an 'intrusion' - either as a factor encroaching on the perpetrators' general ability to get on with their lives or as a specific encumbrance, for example where the offender was required to pay maintenance. In individual cases, the child died in the context of relationship homicide against the mother, either for concealment reasons or because the child happened to come in while the mother was being murdered and the perpetrator more or less spontaneously decided to kill the child as well.

A majority $(n=23)$ of purposeful homicide perpetrators were convicted of murder $(\$ 211 \mathrm{StGB})$, including two who were convicted of twofold and one of threefold murder. The conviction in the remaining cases $(n=11)$ was for manslaughter ( $\S 212 \mathrm{StGB})$, with one conviction for a less severe case of manslaughter ( $\$ 213 \mathrm{StGB})$. Except for one case, all perpetrators received unsuspended prison or juvenile prison sentences and in one case the sentence was combined with placement in a psychiatric hospital ac-

sessment was contained in the file. In one further case, the court refrained from obtaining an expert assessment on account of in-court expertise.

36 In these cases, a person qualified to give such an opinion (e.g. a treating physician or court-appointed expert giving an appraisal based on the file) expressed a suspicion that there was a mental disorder or that various indications (such as a suicide attempt) suggested this to be the case. The information was insufficient, however, for a precise classification to be made. 
cording to $\S 63$ StGB. The final sentences were predominately life sentences $(n=16)$, followed by long prison sentences of more than ten years $(n=7)$; in one case the sentence was between six and ten years. There were no shorter sentences. The picture was similar for the two perpetrators convicted as juveniles - here again, the sentences handed down were in the maximum possible range of six to ten years. There were no acquittals in this case group.

\subsubsection{Neglect}

This smallest case group in terms of numbers comprises 20 victims, and in contrast to most of the other case groups there is not a significant increase in risk in the first six months of a child's life. There is a slightly higher risk for children in the first 15 months, although given the small number of cases this can only be regarded as a tendency. Of the 24 perpetrators, 16 were biological mothers and seven biological fathers; in one case a grandfather was (jointly) convicted. In seven cases, both biological parents were convicted; in all other cases, the victims suffered fatal neglect at the hands of their single mothers. Most offenders were between 21 and 29 years old, four were 18-20, five 30-40 and two over 40 years old. The neglect case group did not include any perpetrators under the age of 18 .

Psychological/psychiatric assessments were compiled on 20 perpetrators in the course of prosecution and nine of these were known to have had mental problems or disorders before the homicide. These included drug problems, depressions and other mental disorders. Likewise nine offenders were found to have a mental problem or disorder at the time of the homicide; personality disorders were identified in five cases and a personality accentuation was identified in one. Individual cases featured depression, drug use and a combination of disorders.

With regard to the triggering event or situation, the homicides can be divided into two groups. Firstly, there are cases were the children were more or less left entirely to their own devices. In the cases committed by single mothers, this neglect often began following separation, in some cases linked with the desire to make a new start. In such cases, the women initially failed to provide sufficiently for the children and later did not take care of them at all, spent their time increasingly and in some cases at the end entirely with friends or with a new partner and left the children behind on their own, where they then died of lack of food or liquid. Other cases 
consisted of medical neglect, where for example parents misjudged a known illness suffered by the child and/or omitted to obtain proper medical treatment. These cases involved chronic illnesses, where the parents failed to administer necessary medication either at all or in sufficient dosage, as well as illnesses that the parents themselves treated with alternative medicine against a doctor's advice. These children died due to failure to provide medical treatment or due to incorrect medical treatment. Where children died as a result of an acute illness, such as an infection, the parents failed to obtain treatment for the children because of a general inability to cope. ${ }^{37}$ In some cases, parents consciously refused to obtain help because they were afraid the children would be taken away from them by social services if the circumstances came out. In isolated cases, the reason for the neglect could not be reconstructed after the event.

Seven perpetrators were convicted of assault resulting in death $(\S 227$ $\mathrm{StGB}$ ), six of manslaughter ( $\$ 212 \mathrm{StGB}$ ) and four of murder (one in two cases), with the murder assumed to be attended with cruelty and in two cases combined with base motives. In all cases, the parents were accused of omission. Five offenders were convicted of involuntary homicide ( $\$ 222$ StGB) and two of maltreatment of charges ( $\$ 225 \mathrm{StGB}$ ), where the parents were accused of actively preventing others from looking after the children's welfare. Sentences were predominantly unsuspended, with 16 prison sentences and three juvenile prison sentences. Only in five cases were suspended sentences handed down and all of these related to prison sentences, i.e. the perpetrators were older than 21 . In one case a juvenile prison sentence was combined with an order for accommodation in a drug rehabilitation centre. The severity of sentencing tended to be high with regard to the prison sentences and in the medium range of four to six years with regard to the juvenile sentences.

\subsection{Summary}

Homicide against children of this age group in Germany is a very heterogeneous phenomenon, with marked differences in motivation and means in some cases extending to within individual case groups. The risk is high-

37 For example because of a difficult family situation, numerous children and/or numerous animals. 
est for children during the first six months and most of all during the first day, with a total of 38.5 percent of children in our sample killed within the first 24 hours after birth. The only case group that shows significant differences in victim gender is the maltreatment group, with 65 percent of victims being male and 35 percent female. The reasons for this heightened risk remain unclear.

The largest case group accordingly consists of neonaticides with over a third of the total, followed by death by maltreatment with upwards of a quarter. With very few exceptions, the perpetrators came from the victims' most immediate social environment and were most usually the biological or social parents. Due to the large number of neonaticides, the biological mothers predominate as offenders (56.5 percent), without this category, their proportion is just slightly higher than 40 percent, followed by the biological fathers with over 38 percent and the social fathers with some 12 percent. In most cases, the perpetrators acted alone, only in 32 cases two or more persons were called to account for the homicide of the child. The offenders were mostly between 21 and 29 years old (42.7 percent), followed by $30-40$ year old persons (30.8 percent).

\section{References}

Beyer, K./McAuliffe Mack, S./Shelton, J. L. (2008). Investigative analysis of neonaticide - An exploratory study. Criminal Justice And Behavior 35, 522-535.

Bijleveld, C./Smit, P. (2006). Homicide in the Netherlands - On the Structuring of Homicide Typologies. Homicide Studies, 10, 195-219.

Bourget, D./Gagné, P. (2002). Maternal filicide in Quebec. Journal of the American Academy of Psychiatry and the Law 30, 345-351.

Bourget, D. /Gagné, P. (2005). Paternal Filicide in Quebec. Journal of the American Academy of Psychiatry and the Law 33, 354-360.

Bozankaya, Nadine (2010). Neonatizid - Die rechtliche Reaktion auf die Tötung Neugeborener - Eine strafrechtliche Untersuchung anhand von Aktenanalysen. Berlin 2010.

Brookman, F./Nolan, J. (2006). The dark figure of infanticide in England and Wales Complexities of diagnosis. Journal of interpersonal violence 7, 869-889.

Daly, M./Wilson, M. (1988). Evolutionary Social Psychology and Family Homicide. Science 242, 519-524.

Daly, M./Wilson, M. (2001). An assessment of some proposed exceptions to the phenomenon of nepotistic discrimination against stepchildren. Annales Zoologici Fennici 38, 287-296. 
Daly, M./Wilson, M. (2005). The "Cinderella effect" - Elevated mistreatment of stepchildren in comparison to those living with genetic parents. Hamilton 2005.

Daly, M./Wilson, M. (2005). The "Cinderella Effect" is no fairy tale. Trends in Cognitive Science 9, 507-508.

D'Orbán, P. T. (1979). Women who Kill their Children. The British Journal of Psychiatry, 134, 560-571.

European Foundation for the care of newborn infants. EU Benchmarking report 2009/2010: Country Highlights. (2010).

Flynn, S./Windfuhr, K./Shaw, J. (2009): Filicide - A Literature Review. Manchester 2009.

Friedman, S.H. [et al.] (2005). Filicide-Suicide - Common Factors in Parents Who Kill Their Children and Themselves. The Journal of the American Academy of Psychiatry and the Law, 33, 496-504.

Häßler, F./Bomke, A.-K./Schläfke, D. (2003). Begutachtungspraxis von Tötungsdelikten - Eine retrospektive Gutachtenanalyse. In: Häßler, F. [et al.] (Eds.). Forensische Kinder-, Jugend- und Erwachsenenpsychiatrie - Aspekte forensischer Begutachtung. Stuttgart, 61-80.

Harris, G. T./Hilton, N. Z./Rice, M. E./Eke, A. W. (2007): Children killed by genetic parents versus stepparents. Evolution and Human Behavior 28, 85-95.

Hatters Friedman, S./McCue Horwitz, S./Resnick, P. J. (2005). Child murder by mothers - a critical analysis of the current state of knowledge and a research agenda. The American journal of psychiatry 162, 1578-1587.

Hempel, Dorothea (2013). Tötungsdelikte an Neugeborenen 1997 bis 2007 in vier deutschen Regionen - Eine Analyse der Risikofaktoren der Kindsmütter. PhD Thesis, University of Jena, 2013.

Herman-Giddens, M. E./Smith, J. B./Mittal, M. [et al.] (2003). Newborns Killed or Left to Die by a Parent - A Population-Based Study. Journal of the American Medical Association 289, 1425-1429.

Hömberg, Sophia Marie (2011). Die Tötung von Kindern durch die eigenen Eltern (Infantizid) - Retrospektive Untersuchung für den Zeitraum 1994-2007. PhD Thesis, University Bonn 2011.

Mariano, T.Y./Chan, H. h./Myers, W. C. (2014). Toward a more holistic understanding of filicide: A multidisciplinary analysis of 32 years of U.S. arrest data. Forensic Science International.

Oberman, M. (2003). Understanding infanticide in context - mothers who kill, 1870-1930 and today. The Journal of Criminal Law and Criminology 92, 707-738.

Paulozzi, L./Sells, M.. (2002). Variation in Homicide Risk during Infancy - United States, 1989-1998. MMWR Weekly.

Porter, T./Gavin, H.. (2010). Infanticide and Neonaticide - A Review of 40 Years of Research Literature on Incidence and Causes. Trauma Violence and Abuse 11, 99-112.

Raic, D. (1997). Die Tötung von Kindern durch die eigenen Eltern - Soziobiographische, motivationale und strafrechtliche Aspekte. Bonn. 
Resnick, P.J. (1969). Child Murder by Parents - A Psychiatric Review of Filicide. The American Journal of Psychiatry, 126, 325-334.

Resnick, P.J. (1970). Murder of a Newborn - A Psychiatric Review of Neonaticide. The American Journal of Psychiatry, 126, 1414-1420.

Schläfke, D. et al. (2003). Zur Problematik von Neonatiziden und Filiziden. In: Häßler, F. et al. (Eds.), Forensische Kinder-, Jugend- und Erwachsenenpsychiatrie - Aspekte der forensischen Begutachtung (pp. 81-102). Stuttgart.

Schlang, C. (2006). Tödlich verlaufende elterliche Gewalt. Bonn.

Schmidt, P., Graß, H., Madea, B. (1996). Child Homicide in Cologne (1985-94). Forensic Science International, 79, 131-144.

Schnitzer, P./Ewigman, B. G. (2005). Child deaths resulting from inflicted injuries household risk factors and perpetrator characteristics. Pediatrics 116, 687-693.

Scott, P. D. (1973). Parents Who Kill Their Children. Medicine, Science and the Law Official Journal of the British Academy of Forensic, 13, 120-126.

Stiffman, M. N./Schnitzer, P.G./Adam, P. [et al.] (2002). Household Composition and Risk of Fatal Child Maltreatment. Pediatrics 109, 615-621.

Strang, H. (1996). Children as Victims of Homicide. Trends and issus in crime and criminal justice.

Temrin, H./Buchmayer, S./Enquist, M. (2000). Stepparents and infanticide - new data contradict evolutionary predictions. Proceedings of the Royal Society 267, 943-945.

Temrin, H./Nordlund, J./Sterner, H. (2004). Are stepchildren overrepresented as victims of lethal parental violence in Sweden? Proceedings of the Royal Society 271, 124-126.

Trube-Becker, E. (1982). Gewalt gegen das Kind Vernachlässigung, Misshandlung, sexueller Missbrauch und Tötung von Kindern. Heidelberg.

Weekes-Shackelford, V. A., \& Shackelford, T. K. (2004). Methods of filicide: Stepparents and genetic parents kill differently. Violence and Victims 19, 75-81.

Vanamo, T./Kauppi, A./Karkola, K. [et al.] (2001). Intra-familial child homicide in Finland 1970-1994 - Incidence, causes of death and demographic characteristic. Forensic Science International 117, 199-204.

Vock, R. (1999). Tödliche Kindesmisshandlung (durch physische Gewalteinwirkung) in der DDR im Zeitraum 1.1.1985 bis 2.10.1990. Archiv für Kriminologie, 204, 75-87.

Vock, R., Meinel, U. (2000). Tödliche Kindesvernachlässigung in der DDR im Zeitraum 1.1.1985 bis 2.10.1990 - Ergebnisse einer multizentrischen Studie. Archiv für Kriminologie, 205, 44-52.

Vock, R., Trauth, W. (1999). Tödliche Kindesmisshandlung (durch physische Gewalteinwirkung) in der Bundesrepublik Deutschland im Zeitraum 1.1.1985 bis 2.10.1990 - Ergebnisse einer multizentrischen Studie. Archiv für Kriminologie, 204, 73-85.

Vogt, K./Block, C. R. (2005). Children's risk of homicide - Victimization from birth to age 14, 1965 to 1995. Research Bulletin 4, 1-16. 
